\title{
Discussion Paper: Commissioning of medical education in the post-registration arena
}

\author{
K. Walsh \& G.D. Rogers ${ }^{2}$
}

\begin{abstract}
Medical education is expensive. In some circumstances, this expense has led to new models of funding post-registration education. One such approach is commissioned or tendered education. This model is based on a purchaser-provider split, where centrally funded authorities commission or seek tenders for post-registration medical education from education providers. Despite the growth of commissioning of medical education, there has been little public debate on its advantages or disadvantages. There are a number of advantages of a commissioning model. It can act as an incentive to quality improvement, and it drives competition between providers. In addition, commissioning decisions can be devolved so that local purchasers can decide what forms of medical education they wish to pay for. It also acts as a means of increasing choice. There are also disadvantages to the commissioning model. The process of commissioning is in itself expensive. In addition, competition might act as a barrier to integration and induce destabilisation in the system of medical education. This model may also suggest that there is a price for everything and that all components of medical education must be reduced to their lowest common denominator of cost. It would work best if pure market forces were unleashed, but the truth is that medical education is rarely a pure market.
\end{abstract}

Keywords: general practice; post-registration training; commissioning; market forces.

\section{The United Kingdom and Australian contexts}

Medical education is expensive (Walsh \& Jaye, 2013). Its expense has led to innovative low cost medical education interventions and to approaches that seek to produce better outcomes for a stable cost (Walsh, Rutherford, Richardson, \& Moore, 2010). However, these interventions have thus far been limited in their impact (Sandars, 2010). In some circumstances, the absolute costs have led to new models

1 BMJ Learning, BMJ Group, London

2 School of Medicine and Health Institute for the Development of Education and Scholarship, Griffith University, Queensland

Correspondence

Dr Kieran Walsh

Clinical director-BMJ Learning and Quality

BMJ, BMA House, Tavistock Square

London, WC1H 9JR

Tel: +442073836550

Email: kmwalsh@bmj.com

Website: bmj.com/company 
for the funding of medical education. One example is the model whereby medical education activities are commissioned or made the subject of a tender process. This is based on a purchaser-provider split within medical education-in essence this means that centrally funded authorities, such as local education boards in the United Kingdom or the Australian General Practice Training program in Australia, purchase or commission post-registration medical education from education and clinical care providers. Such providers might be hospitals, primary care units or regional training organisations formed for this purpose. They could be commissioned or might equally be decommissioned, with their status as a provider (and funds) withdrawn. This model has gained acceptance in post-registration medical education within England and has recently been introduced for general practice training in Australia. However, despite the growth of commissioning of medical education, there has been remarkably little public debate on whether this model is an effective one or advantageous. In this short article, we outline some advantages and disadvantages, as well as suggesting some ways in which advantages might be accentuated and disadvantages minimised.

One of the main arguments in favour of a purchaser-provider split in medical education is that it can act as an incentive for quality improvement. Providers of medical education need to put together convincing bids to be commissioned or succeed in a tendering process. They must ensure that they deliver what they have promised and must be able to demonstrate the effectiveness of their approach. Thus, commissioning should ensure accountability amongst providers of medical education, something which is increasingly seen as important (Murray, Gruppen, Catton, Hays, \& Woolliscroft, 2000). Providers must be able to deliver value - good quality at an affordable cost - to retain their positions as funded providers.

Another advantage of commissioning medical education is said to be that it drives competition between providers. Open and fair competition should mean that the medical education provider that can best meet the criteria that the purchaser requires would win the commission. These criteria might be related to quality, productivity, cost, other factors or, indeed, a weighted combination of such factors. However, these should all result in value-ultimately, value to the purchaser and, thus, to the public (Zendejas, Wang, Brydges, Hamstra, \& Cook, 2013).

Thirdly, commissioning decisions in the UK context could be devolved so that local purchasers can decide what forms of medical education they wish to pay for based on the final analysis of local population needs. Thus, a local board in a rural location with a shortage of general practitioners might commission a consortium of primary care providers to produce more post-registration general practice education and, as a result, more general practitioners. Therefore, commissioning could act as a lever to ensure that medical education is aligned with local workforce needs. All too often such alignment is not what it should be (Frenk et al., 2010).

Commissioning also acts as a means of increasing choice for the purchaser. A marketplace in medical education might mean that more providers will emerge as they envisage a reasonable opportunity for themselves to be winners in a competitive framework. A range of different providers of medical education could, thus, emerge. These providers 
might be in primary or secondary care, be high cost or low cost, be high technology or low technology, or they might be a combination of these permutations. Regardless of this, there is no doubt that more choice should emerge for the purchaser.

There do appear to be benefits to a commissioning model in post-registration medical education; however, there are also a number of disadvantages.

Commissioning may result in a high quality, low cost provider winning an education contract; however, the costs of commissioning or tendering itself must be added to the cost of the provision. Commissioning will involve open competition and will thus incur a range of costs. These include legal costs and the costs of tendering, judging and deciding the winner, contracting, and monitoring the delivery of any contract. Some of these costs would be borne by the commissioning authority directly. Others would be met by the applicants, but these costs - and the associated risk should the applicant not be successful - are likely to be factored into the minimum price that a provider would be willing to accept. The additional costs appear likely to be substantial and, indeed, might outweigh any intended savings that were meant to be achieved by means of commissioning.

Commissioning naturally encourages competition between potential providers; however, this very competition might act as a barrier to integration-and integration might be of key importance in the provision of post-registration medical education. For example, a teaching hospital might compete with a general hospital to be able to provide education to trainee geriatricians. However, it might emerge that the geriatricians that are required at the end of the training program (the output) need to have clinical, academic, teaching, leadership and research skills. They can only attain these skills by means of working in rotations in the teaching hospital and the general hospital. How, then, are the general hospital and teaching hospital to compete with each other? The simple truth is that they will not be able to.

Commissioning will have an influence on competition, but this influence may induce unwanted destabilisation in the system of medical education and, indeed, clinical care. A hospital may have been providing medical education for post-registration trainees for many years. It receives funding for this, and at the same time, the trainees deliver some of the service at the hospital. However, let's imagine for an instant that training at the hospital is decommissioned. The hospital will lose funding; it will lose its trainees; and it will lose the doctors who have been providing care. How will the hospital be able to continue its patient care function into the future?

Commissioning, like any other process, is only as good as the way in which it is conducted. In the wrong hands, the levers of commissioning may drive down quality as well as cost. Commissioning, if it is used at all, should be used as a means of driving quality and should not be seen only as a means for savings costs.

Commissioning may also change the culture of medical education. Part of the hidden curriculum among post-registration training programs may be that there is a price for everything and that all components of medical education and, indeed, clinical care must be reduced to their lowest common denominator of cost. Through this hidden 
curriculum, post-registration trainees may learn the unintended lesson that medical education, and by implication healthcare, are commodities to be bought and sold by any provider or purchaser, and at any price (ANZAHPE, 2014). Certainly, outside of the topic of commissioning, it is true that it is the hidden curriculum that is the one that has most impact (Hafferty, 1998).

A final disadvantage of commissioning is that it works best when pure market forces are unleashed, and the simple truth is that medical education is rarely, if ever, a pure market (Roberts, 1987). In a pure market, purchasers and providers are unrelated to each other; however, in medical education commissioning, the separation of purchaser and provider is artificial-they are both ultimately funded by the public purse. In a pure market, there is the potential for profit for providers, but in medical education commissioning, it is really a matter of public funds moving around a system for questionable purposes. In a pure market, there is no monopoly or oligopoly of providers. However, in medical education, there may be limited options for a purchaser to choose from-in effect, there may be a monopoly or oligopoly of provision. In a pure market, there are no barriers to entry or exit for providers; however, in medical education, the barriers to entry may be impossibly high. For example, it might not be feasible to set up a hospital to provide care for patients and education for trainees. Similarly, it might not be feasible for providers to exit the market and for a hospital to decide that it will no longer provide education for trainees. The commissioning marketplace for medical education is to some degree an unreal marketplace, and this can render commissioning ineffective as a tool to drive quality or control cost.

Do the advantages outweigh the disadvantages? It is difficult to tell, particularly since there is a lack of evidence base. There is also a lack of theoretical underpinning of the model. Ultimately, it all probably depends on the circumstances and how commissioning is conducted. What has been published on the subject thus far is mainly opinion (Sandars \& Walsh, 2005), as this is. What is surprising, however, is the degree to which the practice of commissioning education has infiltrated many different environments with relatively little discourse on whether it should. Before it is rolled out further, it would be wise to have more debate, investigate whether the theoretical foundations of commissioning models are a good fit with medical education and conduct research on the effectiveness of various models of commissioning.

\section{References}

Australian and New Zealand Association for Health Professional Educators (ANZAHPE) (2014). Gold Coast declaration on learning through practice in the health professions. Retrieved from http://media.wix.com/ugd/363deb_ acff357111d84498b177b7bb32dc8e03.pdf

Frenk, J., Chen, L., Bhutta, Z. A., Cohen, J., Crisp, N., Evans, T., . . Zurayk, H. (2010). Health professionals for a new century: Transforming education to strengthen health systems in an interdependent world. Lancet, 376(9756), 19231958. doi:10.1016/S0140-6736(10)61854-5 
Hafferty, F. W. (1998). Beyond curriculum reform: Confronting medicine's hidden curriculum. Academic Medicine, 73(4), 403-407.

Murray, E., Gruppen, L., Catton, P., Hays, R., Woolliscroft, J. O. (2000). The accountability of clinical education: Its definition and assessment. Medical Education, 34(10), 871-879.

Roberts, J. (1987). Perfectly and imperfectly competitive markets. In J. Eatwell, M. Milgate, \& P. Newman (Eds.), The new Palgrave: A dictionary of economics. New York, NY: Macmillan.

Sandars, J. (2010). Cost-effective e-learning in medical education. In K. Walsh (Ed.), Cost effectiveness in medical education. Abingdon, UK: Radcliffe.

Sandars, J., \& Walsh, K. (2005). A consumer guide to the world of e-learning. BMJ Career Focus, 330, 96-97.

Walsh, K., \& Jaye, P. (2013). Cost and value in medical education. Education for Primary Care, 24(6), 391-393.

Walsh, K., Rutherford, A., Richardson, J., \& Moore, P. (2010). NICE medical education modules: An analysis of cost-effectiveness. Education for Primary Care, 21(6), 396-398.

Zendejas, B., Wang, A. T., Brydges, R., Hamstra, S. J., \& Cook, D. A. (2013). Cost: The missing outcome in simulation-based medical education research. A systematic review. Surgery, 153(2), 160-176. doi:10.1016/j.surg.2012.06.025 